\title{
Structural Basis of DEAH/RHA Helicase Activity
}

\author{
Michael C. Chen ${ }^{1,2}$ and Adrian R. Ferré-D'Amaré ${ }^{1, *}$ \\ 1 Biochemistry and Biophysics Center, National Heart, Lung and Blood Institute, Bethesda, MD 20892, USA; \\ michael.chen@nih.gov \\ 2 Department of Chemistry, University of Cambridge, Cambridge CB2 1EW, UK \\ * Correspondence: adrian.ferre@nih.gov; Tel.: +1-301-496-4096
}

Academic Editor: Jinwei Zhang

Received: 6 July 2017; Accepted: 13 August 2017; Published: 15 August 2017

\begin{abstract}
DEAH/RHA helicases are members of a large group of proteins collectively termed DExH-box, which also include Ski2-like and NS3/NPH-II helicases. By binding and remodeling DNA and RNA, DEAH/RHA helicases play critical roles in many cellular processes ranging from transcription and splicing to ribosome biogenesis, innate immunity and stress granule formation. While numerous crystal structures of other DExH-box proteins helicases have been reported, no structures of DEAH/RHA helicases bound to nucleic acid substrates have been available until the recent co-crystal structures of the maleless (MLE) and Prp43p bound to RNA. This review examines how these new structures provide a starting point to understand how DEAH/RHA helicases bind to, translocate on, and unwind nucleic acid substrates.
\end{abstract}

Keywords: DEAH/RHA; DExH; helicase; MLE; Prp43p; DHX36; HCV NS3

\section{Introduction}

DEAH/RHA helicases belong to a group of SF2 helicases collectively called DExH-box proteins, which additionally consist of the following families: Ski2-like and NS3/NPH-II [1-3]. DEAH/RHA helicases are implicated in both DNA and RNA processes, including transcription regulation, innate immunity, stress granule formation, RNA splicing, ribosome biogenesis, and translation regulation [4-14]. Due to the crucial roles of DEAH/RHA helicases and DEAD/DExH helicases in general, aberrant regulation of these helicases have often been identified as contributors to various diseases, such as cancer or neurological disorders [15-19].

Structurally, and like all SF1 and SF2 helicases, the cores of DEAH helicases are comprised of two RecA-like domains (RecA1 and RecA2) [20]. Together, these present a nucleotide $5^{\prime}$-triphosphate (NTP) binding cleft and a single-stranded nucleic acid binding surface. DEAH/RHA helicases additionally have several C-terminal sub-domains, and often also N-terminal extensions (NTE). Typically, the C-terminal domain consist of a degenerate winged-helix (WH), ratchet-like (RL), and OB-like fold (OB) sub-domains, as shown in Figure 1 [20-22]. In addition, a C-terminal extension (CTE) that stabilizes an NTE through the joint formation of a three-helix bundle may be present [23]. The structure of maleless (MLE), the Drosophila melanogaster ortholog of hDHX9, shows that this interaction orients the NTE (a double-stranded RNA-binding domain in that helicase) toward the $5^{\prime}$-end of a structured nucleic acid substrate (Figure 1b) [23].

The NTE of DEAH/RHA helicases typically imparts specificity for the secondary structure of their substrate nucleic acids, and is often necessary, if not sufficient, for binding to structured nucleic acids substrates [24-27]. For instance, in the case of DHX36, the NTE gives rise to the specificity of the helicase for G-quadruplex-containing DNA and RNA, even though the isolated NTE binds to substrates (with greatly diminished affinity when compared to the full-length protein) [26,27]. 
Amongst DEAD/DExH helicases, the DEAD and Ski2-like helicases possess a glutamine motif (Q-motif) in the RecA1 domain that provides specificity for ATP [28]. DEAH/RHA helicases and NS3/NPH-II like helicases do not contain a Q-motif. As such, DEAH/RHA helicases are capable of binding and hydrolyzing other nucleotide $5^{\prime}$-triphosphates. This was recently visualized crystallographically in the X-ray structure of Prp43p bound to CDP [29]. Additionally, DEAH/RHA, Ski2-like, and NS3/NPH-II helicases are characterized by the presence of a prominent $\beta$-hairpin (HP motif) between motif V and VI in the RecA2 domain [21,22,30-32]. In the Ski2-like helicase, Hel308, the $\beta$-hairpin, stacks against the last base pair of the co-crystallized DNA duplex [32]. The $\beta$-hairpin is thus proposed to act as the unwinding element in the Ski2-like family [32]. The general domain organization and architecture of the ATP-binding cleft of DEAH/RHA helicases was previously reviewed [20], so we do not cover this topic further in this review.

Biochemical analyses show that despite a shared domain architecture, different DExH-box proteins display disparate translocation and unwinding mechanisms [33-42]. For example, the NS3/NPH-II helicase, HCV NS3, is capable of rapidly translocating across hundreds of nucleotides at up to 74 nucleotides per second [43], whereas the DEAH/RHA helicase, DHX36, locally unwinds a G-quadruplex and rapidly dissociates thereafter $[34,38]$. While numerous helicase structures have been reported, no structures of DEAH/RNA helicases bound to nucleic acid substrates were available until the recent structure determinations of MLE [23] and Prp43p [44,45] bound to RNA. These provide a starting point to understand how DEAH/RHA helicases bind, translocate, and unwind nucleic acid substrates.
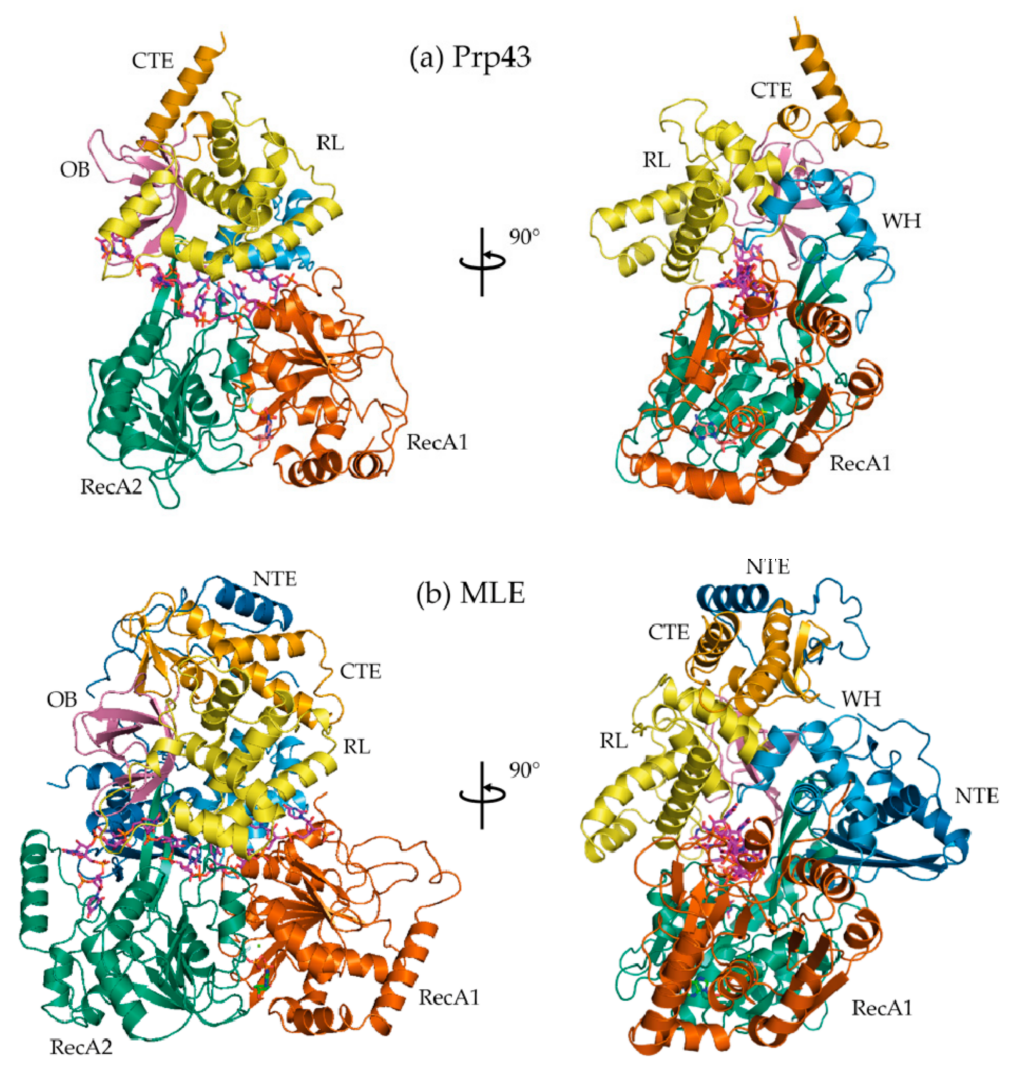

Figure 1. Co-crystal structures of (a) ground state Prp43p bound to an RNA substrate $\mathrm{rU}_{16}$ and ADP. $\mathrm{BeF}_{3}{ }^{-}$(Prp43p-rU-GR; DHX15; PDB 5LTA) and (b) transition state-mimic MLE bound to an RNA substrate $\mathrm{rU}_{15}$ and $\mathrm{ADP} \cdot \mathrm{AlF}_{4}{ }^{-}$(MLE-rU-TR; DHX9; PDB 5AOR). A co-crystal structure is also available of a ground state Prp43p bound to an RNA substrate $\mathrm{rU}_{25}$ and AMP-PNP (PDB 5I8Q). Abbreviations are as follows: $\mathrm{OB}-\mathrm{OB}$-like fold sub-domain, $\mathrm{RL}$-ratchet-like sub-domain, $\mathrm{WH}$-degenerate winged-helix sub-domain, NTE-N-terminal extension, and CTE-C-terminal extension. 


\section{Crystallographic Snapshots of DEAH/RHA Helicases}

Many NTPases have been co-crystallized with NTP analogs in an effort to freeze protein conformations along the NTP hydrolysis reaction coordinate [46,47]. MLE and Prp43p were crystallized bound to RNA in the presence of the ATP analogs $\mathrm{ADP} \cdot \mathrm{AlF}_{4}{ }^{-}$, and AMP-PNP and $\mathrm{ADP} \cdot \mathrm{BeF}_{3}{ }^{-}$, respectively. Generally in the use of NTP analogs, the assumption is that transient helicase conformations and the subsequent effects on the nucleic acid substrate can be visualized as a function of the trapped ATP hydrolysis state. Commonly employed ATP mimics include ADP in complex with $\mathrm{BeF}_{3}{ }^{-}, \mathrm{AlF}_{4}{ }^{-}$, and $\mathrm{VO}_{4}{ }^{3-}$, which replace the $\gamma$-phosphate (Figure 2) [48]. ADP. $\mathrm{BeF}_{3}{ }^{-}$ complexes adopt a tetrahedral conformation that is isosteric to the $\gamma$-phosphate in the Michaelis complex [49]. As such, helicase structures containing $\mathrm{BeF}_{3}{ }^{-}$complexes are considered to represent a ground state or pre-hydrolysis state (Figure $2 \mathrm{~b}$ ) [49]. $\mathrm{ADP} \cdot \mathrm{BeF}_{3}{ }^{-}$is highly useful in interrogating helicase-unwinding mechanisms because ATP hydrolysis does not necessarily need to correspond with nucleic acid secondary structure unwinding or displacement. Mss116p, a DEAD-box helicase, is capable of unwinding its dsRNA substrate in the presence of $\mathrm{ADP} \cdot \mathrm{BeF}_{3}{ }^{-}$, indicating that DEAD-box ATP hydrolysis facilitates substrate release [50,51].

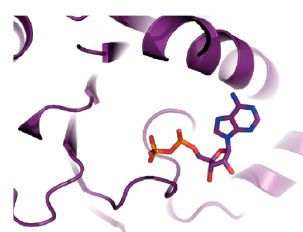

(a) ADP - post-hydrolysis

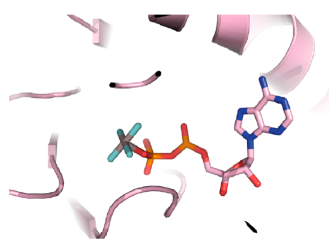

(c) $\mathrm{ADP}_{\mathrm{AlF}}$ - transition

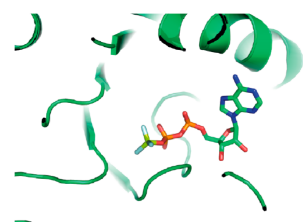

(b) $\mathrm{ADP} \mathrm{BeF}_{3}$ - ground

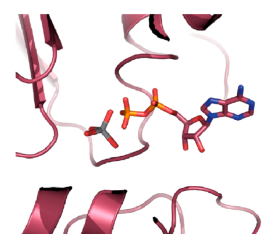

(d) $\mathrm{ADP}_{\mathrm{VO}_{4}}$ - transition

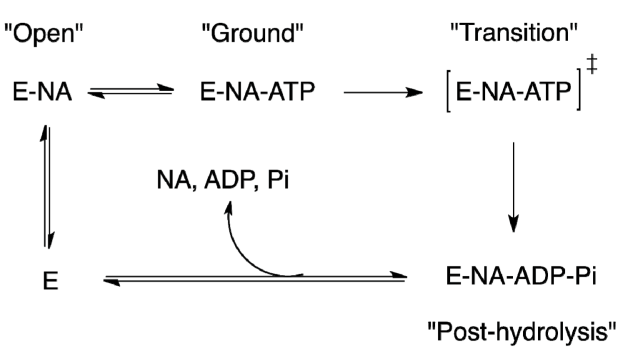

(e) ATP utilization schematic

Figure 2. ATP analogs used to capture hydrolases at different points along the ATP hydrolysis reaction pathway. (a) ADP represents the post-hydrolysis state. ADP is typically rapidly released from the ATP

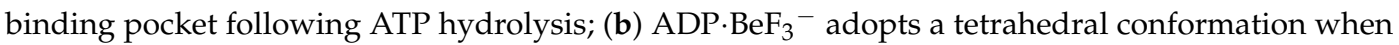
complexed with the $\beta$-phosphate in the active site. The tetrahedral conformation mimics a ground-state, or pre-hydrolysis species; (c) $\mathrm{ADP} \cdot \mathrm{AlF}_{4}{ }^{-}$adopts an octahedral conformation when complexed with the $\beta$-phosphate and a nucleophilic water species in the active site. $\mathrm{ADP} \cdot \mathrm{AlF}_{4}{ }^{-}$is a pseudo-mimic of the ATP hydrolysis transition state as the true transition state adopts a trigonal bipyramidal conformation; (d) $\mathrm{ADP} \cdot \mathrm{VO}_{4}{ }^{3-}$ adopts an imperfect trigonal bipyramidal conformation when complexed with the $\beta$-phosphate oxygen; (e) A reaction schematic summarizing the use of ATP by a helicase in the presence of a nucleic acid substrate.

$\mathrm{ADP} \cdot \mathrm{AlF}_{4}{ }^{-}$and $\mathrm{VO}_{4}{ }^{3-}$ are commonly employed as transition-state mimics of ATP hydrolysis $[48,51]$. ADP $\cdot \mathrm{AlF}_{4}{ }^{-}$adopts an octahedral geometry, where the four fluorines are equatorial and the $\beta$-phosphate terminal oxygen as well as a water molecule are axial (nucleophilic water is not shown but is present in the crystal structure; Figure 2c) [49]. However, a caveat of ADP.AlF $4{ }^{-}$as a $^{-}$ transition-state mimic is that the hydrolysis of the $\gamma$-phosphate of ATP proceeds through a trigonal planar transition state; thus the octahedral coordination around aluminum in $\mathrm{ADP} \cdot \mathrm{AlF}_{4}{ }^{-}$is just an approximation [48]. Yet, $\mathrm{ADP} \cdot \mathrm{AlF}_{4}{ }^{-}$remains the most widely used transition state analog in helicase biochemistry and structural biology. The oxygen atoms around the vanadium in $\mathrm{ADP}^{\mathrm{VO}} \mathrm{VO}_{4}{ }^{3-}$ adopt a trigonal bipyramidal geometry, which better approximates the hydrolysis transition state (Figure 2d) [48]. 


\section{DEAH/RHA RecA1 Interactions}

The co-crystal structures of MLE (MLE-rU-TR) [23] and Prp43p (Prp43p-rU-GR) [44,45] bound to RNA substrates in the transition and ground states, respectively show that, like other SF2 helicases, DEAH/RHA helicases interact with their nucleic acid substrate via the helicase core region typically through three motifs in the RecA1 domain at the $3^{\prime}$-end and four motifs in the RecA2 domain at the $5^{\prime}$-end. In the RecA1 domain, (1) Ia, (2) Ib (hook-turn [44]), and (3) Ic interact with the $3^{\prime}$-end of the nucleic acid substrate.

From the co-crystal structures of MLE-rU-TR and Prp43p-rU-GR, motif Ia provides two consecutive Arg residues that form a "pincer" surrounding the sugar-phosphate backbone of the substrate nucleic acid (Figure 3b,c) [23,44,45]. In HCV NS3, the homologous residue in motif Ia is a serine, the mutation of which does not result in deleterious effects [52]. On the other hand, the mutation of the motif Ia arginine (the C-terminal arginine) in Prp43p results in a cold-sensitive phenotype in S. cerevisiae, indicating motif Ia is important for Prp43p helicase activity [53]. This motif is at the $\mathrm{N}$-terminus of the helix that provides a tyrosine in NS3/NPH-II helicases (Y motif) or an arginine in DEAH/RHA helicases (R motif), which stacks with the base of the NTP in the NTP binding cleft. It has been proposed that this helix acts as a "spring" transducing NTP hydrolysis to nucleic acid substrate coordination via motif Ia in NS3/NPH-II helicases [20]. No evidence is available that demonstrates the DEAH/RHA motif Ia-R helix acts in a spring-like fashion; a systematic series of DEAH/RHA-nucleic acid co-crystal structures in complex with and without ATP analogs will be required to address this question. The motif Ic helix, which is adjacent to $\mathrm{WH}$, typically provides the most extensive contacts between the RecA1 domain and the nucleic acid substrate. The highly conserved motif Ic threonine and arginine residues form non-specific interactions with the sugar-phosphate backbone and the latter additionally stacks with a base of the substrate nucleic acid (Figure 3b,c).

In NS3/NPH-II and DEAH/RHA helicases, motif Ib (hook-turn) contains a $\beta$-hairpin motif that interacts with the substrate nucleic acid sugar-phosphate backbone along the RecA1 substrate nucleic acid binding interface (Figure 3). The importance of motif $\mathrm{Ib}$ was first identified by the structure guided mutation of motif $\mathrm{Ib}$ residues in Prp43p (arginine-phenylalanine), which resulted in an impairment of helicase unwinding activity without affecting NTPase activity [53]. In the co-crystal structures of Prp43p bound to ADP, motif Ib in DEAH/RHA helicases was shown to adopt a similar elongated $\beta$-hairpin to that of HCV NS3 [21,22]. Subsequently, the MLE-rU-TR structure demonstrated that a motif $\mathrm{Ib}$ arginine interacted with the sugar-phosphate backbone and formed part of the $3^{\prime}$ substrate nucleic acid channel [23]. In Prp43p-rU-GR, motif Ib adopts a nearly identical configuration to MLE, where motif Ib is proposed to act as a "3'-bookend" [45] or a "hook-turn" [44] that is crucial for Prp43p translocation. As the motif $\mathrm{Ib}$ arginine residue is conserved amongst DEAH/RHA helicases, motif $\mathrm{Ib}$ along with Ia and Ic contribute to the translocation and unwinding activity of all DEAH/RHA helicases. 
(a) HCV NS3

(b) Prp43p

(c) MLE
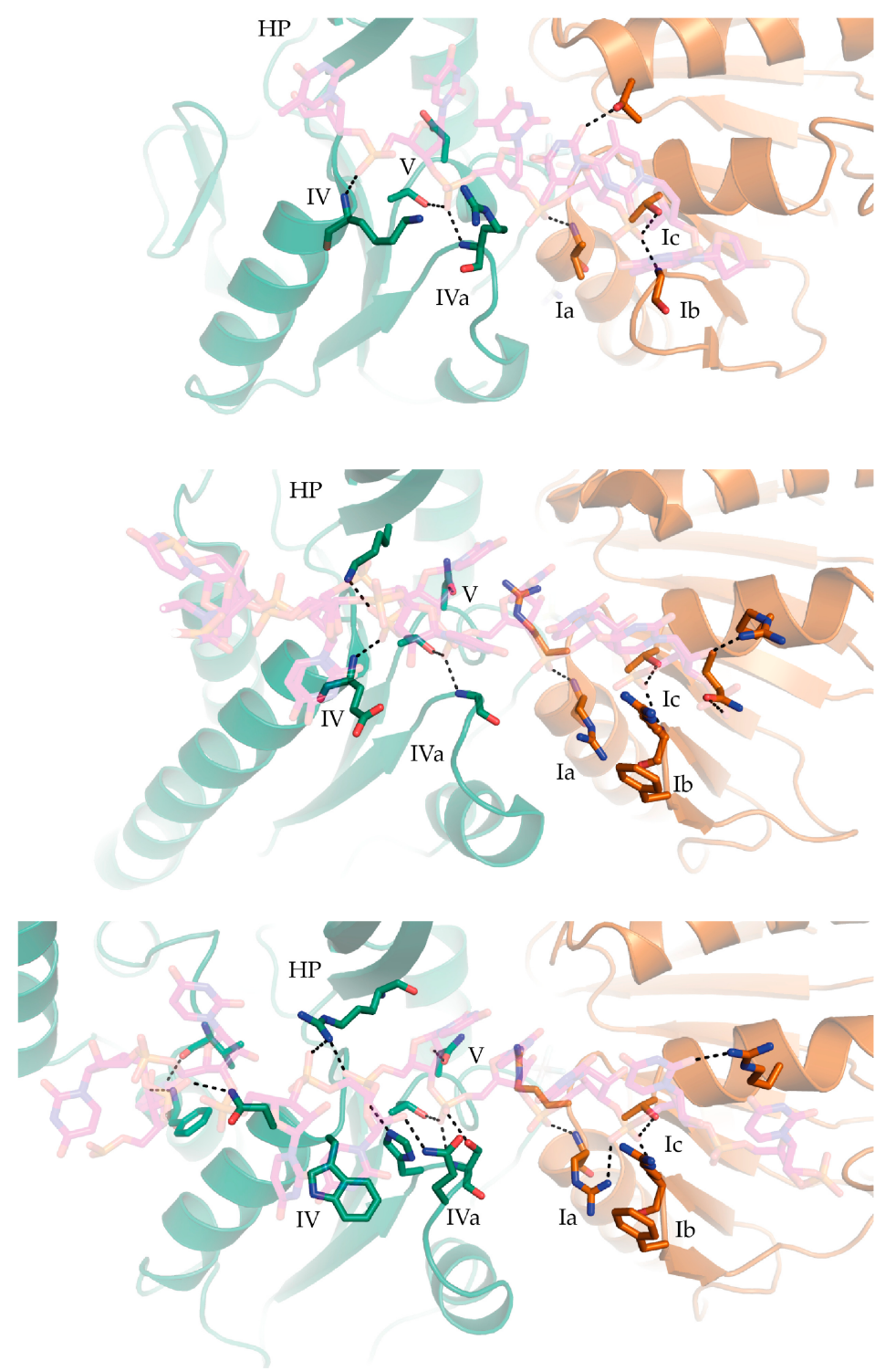

Figure 3. Interactions between a bound single-stranded nucleic acid substrates and the RecA1/RecA2 domains (brown and green, respectively) of (a) HCV NS3 (PDB 3KQL); (b) C. thermophilum Prp43p (DHX15; PDB 5LTA); and (c) MLE (D. melanogaster DHX9; PDB 5AOR). (HP stands for $5^{\prime} \beta$-hairpin).

\section{DEAH/RHA RecA2 Interactions}

In the RecA2 domain, (1) IV, (2) IVa (hook-loop [23]), (3) V, and (4) HP motifs interact with the $5^{\prime}$-end of the nucleic acid substrate. Amongst DEAH/RHA helicases, motif V is highly conserved. Motif $\mathrm{V}$ consecutively provides a threonine and asparagine, which chelate the phosphate oxygen and $2^{\prime}-\mathrm{OH}$ of the same nucleotide in the helicase core region "closed" ground and transition states (Figures 2e and 3b,c). While many DEAH/RHA helicases bind and unwind both DNA and RNA substrates, contacts provided by motif $\mathrm{V}$ explain why DEAH/RHA helicases typically display slightly higher affinities for RNA substrates [54,55]. As described in the following section, the motif $\mathrm{V}$ loop is mobile as it is part of the same loop that provides a threonine that stacks against the nucleobase of the NTP in its binding cleft (Figure 3b,c) [23,44,45]. In NS3/NPH-II helicases and likely amongst DEAH/RHA helicases, this loop motion results in the transition between the "open" and "closed" helicase core region conformation upon binding an NTP molecule [52,56]. In the post-hydrolysis state (Prp43p-ADP shown in Figure 4c), a phenylalanine from a loop directly 
C-terminal to the hook loop impinges upon the motif V threonine in the NTP binding cleft, resulting in a sandwich of the NTP base between a phenylalanine from RecA2 and an arginine from RecA1 [21,22]. The resulting conformational rearrangement of motif $\mathrm{V}$ and the hook-loop result in a helicase core region conformation that is not conducive to nucleic acid binding, as has been shown biochemically with DEAH/RHA helicases [21,22]. The post-hydrolysis conformation that allows Prp43p and DEAH/RHA helicases in general to processively translocate on a nucleic acid substrate is currently unknown. Through an as of yet structurally uncharacterized interaction, Prp43p through its OB sub-domain interacts with G-patch proteins such as Ntr1p, Pfa1p, and Gno1p to become processive translocases [29,57-59].

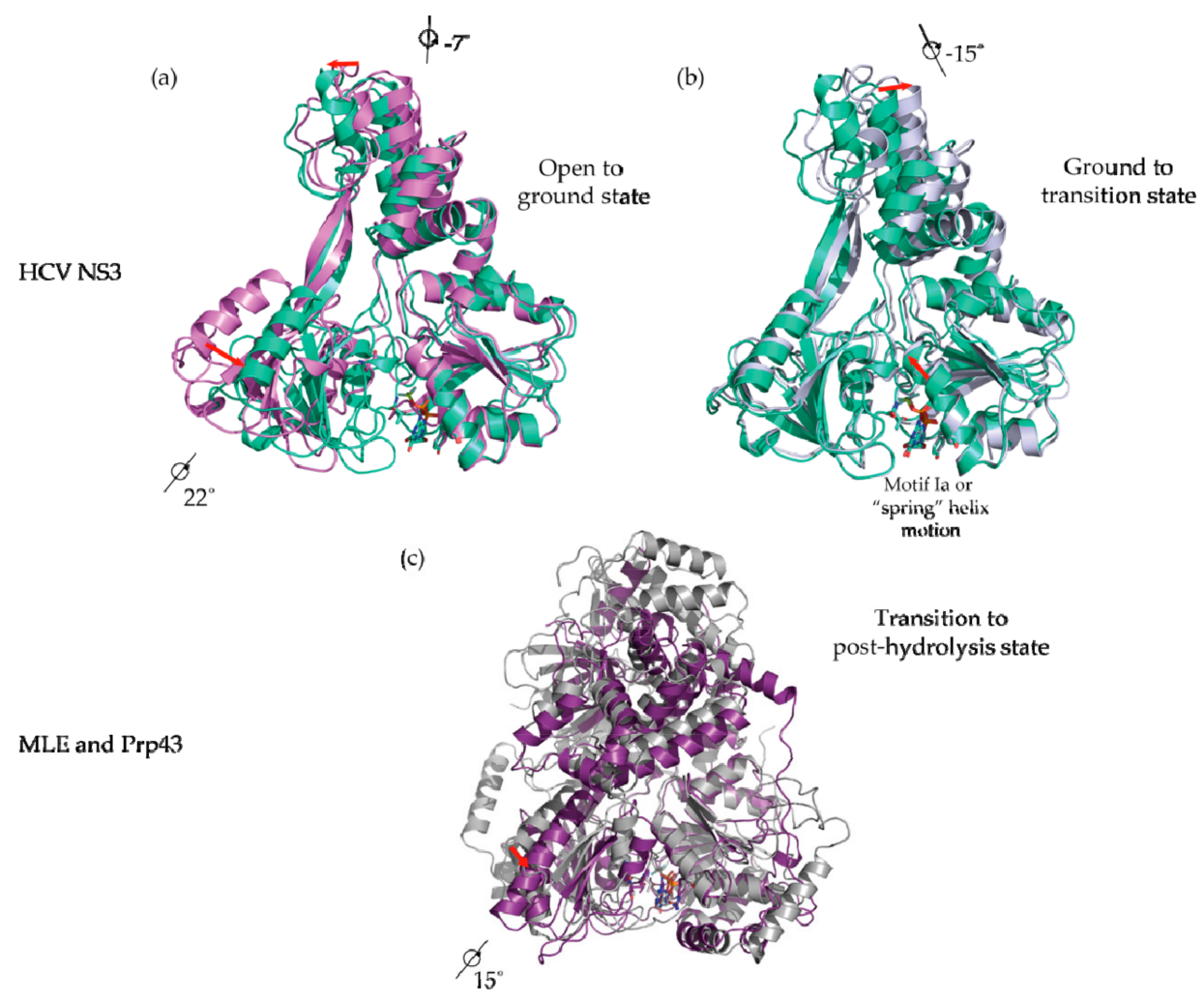

Figure 4. Use of ATP analogs to study DExH-box helicase structural mechanisms. (a) Crystal structure of HCV NS3 complexed to ssDNA without ATP analogs (PDB 3KQK; purple; open state; NS3-apo) superimposed via RecA1 with HCV NS3 bound to ADP $\mathrm{BeF}_{3}^{-}$(PDB 3KQN; green; ground state; NS3-Be). A rotation of RecA2 and CTD is evident; (b) Crystal structure of HCV NS3 bound to $\mathrm{ADP} \mathrm{BeF}_{3}{ }^{-}$(green) superimposed via RecA1 with $\mathrm{HCV}$ NS3 bound to ADP $\mathrm{AlF}_{4}{ }^{-}$(PDB 3KQL; silver; transition state; NS3-Al). A rotation of CTD and intra-domain movements in RecA1 are evident; (c) Crystal structure of MLE bound to ssRNA and ADP $\mathrm{AlF}_{4}^{-}$(PDB 5AOR; silver; transition state; MLE-rU-TR) superimposed via RecA1 with Prp43p bound to ADP (PDB 2XAU; purple; post-hydrolysis state; Prp43p-ADP). Rotation of RecA3 is evident.

The sequence of motif IV and IVa (hook loop [23]) are less conserved amongst DEAH/RHA helicases. Sequence conservation divides the DEAH/RHA helicase family into two phylogenetic groups: DEAH helicases that contain the residues D-E-A-H in motif II and RHA helicases that contain the residues D-E-X-H, where $\mathrm{X}$ is most often isoleucine. In RHA helicases such as MLE, motif IV typically contains a tryptophan, which stacks against a substrate nucleic acid nucleobase with its indole and contacts a phosphate oxygen using its backbone amide (Figure 3c). Motif IVa consists of the residues H-S-X, which make extensive contacts with the sugar-phosphate backbone of two nucleotide residues. Mutagenesis showed motif IVa to be necessary for MLE unwinding activity. Due to the 
importance of motif IVa for unwinding activity in MLE, it was proposed that the RecA2 domain "drags" the nucleic acid substrate into the helicase core [23].

In DEAH helicases such as Prp43p, motif IV only provides a glutamate residue that makes a peptide backbone contact with the phosphate oxygen of the RNA substrate (Figure $3 b$ ). The interaction between the hook-loop and the RNA substrate consists solely of a main-chain H-bond between a glycine residue and a phosphate oxygen. In Prp43p, the hook-loop was found to be dispensable for helicase activity [44]. The accounting of interactions between the RecA2 domain and the nucleic acid substrate shows that DEAH helicases do not interact as strongly with their nucleic acid substrate through the RecA2 domain when compared with RHA helicases.

In Ski2-like helicases the HP motif directly separates the two strands of a nucleic acid duplex [32,60,61], whereas in DEAH/RHA helicases the HP motif appears to be out of position to perform such a role due to extensive protein-protein contacts with the OB sub-domain. However, in both MLE and Prp43p, the HP motif sterically occludes the path of the nucleic acid substrate resulting in an abrupt flip of the nucleotide bases so that the bases are pointing away from the HP motif (Figure 3b,c). This flipped structure is unlike what is observed in both Ski2-like and NS3/NPH-II helicases where the nucleotides point towards the HP motif (Figure 3a) $[30,32,52,56,60]$. Thus, the HP motif may nevertheless play a role in substrate unwinding by providing strain directly $3^{\prime}$ to any nucleic acid secondary structure.

\section{Conformational Snapshots of HCV NS3 Through the Use of ATP Analogs}

A series of conformational "snapshots" of the hepatitis C (HCV) NS3 helicase, which were obtained through the use of ground- and transition-state ATP analogs, have been reported bound to DNA [52] and RNA [56] substrates. The pattern of H-bonding between the helicase core region and the nucleic acid substrate within both DEAH/RHA helicases and the HCV NS3 helicase are highly conserved. Due to this conservation, He and colleagues predicted that the open and closed states of the HCV NS3 helicase core region will closely mirror that of DEAH/RHA helicases as a function of ATP reaction coordinate [45]. In a study performed by Rice and colleagues, HCV NS3 was co-crystallized with ssDNA and either bound to (1) no ATP analog (NS3-apo); (2) ADP. $\mathrm{BeF}_{3}{ }^{-}$ (NS3-Be); or (3) $\mathrm{ADP} \cdot \mathrm{AlF}_{4}{ }^{-}$(NS3-Al) [52].

When the NS3-apo is superimposed on the NS3-Be (ATP-binding step), an $\sim 22^{\circ}$ rotation of the RecA2 and an $\sim 7^{\circ}$ rotation of the HCV NS3 CTD is apparent (Figure 4a). The ATP-dependent rotation is interpreted as a structural transition from an "open" to a "closed" conformation, a phenomenon common to most SF1 and SF2 helicases when bound by an ATP analog, but notably this transition has not yet been structurally observed in the DEAH/RHA family. Superposition of the NS3-Be with NS3-Al (ATP-hydrolysis step) reveals an $\sim 15^{\circ}$ rotation for the NS3 CTD about the axes shown in Figure $3 \mathrm{~b}$ and intra-domain movement of the RecA1 domain. The top half of RecA1 rotates along an axis orthogonal to the rotation axis for CTD and the top of RecA1, resulting in the "stretching" of an alpha helix-containing motif $Y$ (Figure $4 \mathrm{~b}$, red arrows). Motif $Y$ contains a tyrosine residue that $\pi-\pi$ stacks below the adenine base of the ATP analog. As mentioned above, this motif is hypothesized to transduce ATP binding and hydrolysis events to conformational changes in the nucleic acid substrate within NS3/NPH-II helicases [52,62].

The large conformational changes in RecA1 and RecA2 power a ratcheting inchworm motion that result in unidirectional $3^{\prime}-5^{\prime}$ translocation along an ssDNA or ssRNA substrate, as shown in Figure 5a [52]. RecA1 and RecA2 form a binding surface for a single-stranded nucleic acid substrate with a footprint of five nucleotides. Prior to ATP-binding (NS3-apo), RecA2 makes contact with the substrate phosphates of nucleotides $1-3$ and RecA1 contacts those of nucleotides $4-5$ (Figure $5 \mathrm{~b}$ top). After ATP binding (NS3-Be), RecA1-RecA2 closure as a result of RecA2 rotation results in RecA2 contacting nucleotide phosphates 1-2 and the RecA1 binding surface sliding $3^{\prime}$ to $5^{\prime}$ to contact only nucleotide 4 (Figure 5b second from the top). During ATP binding, the spring helix residue V232 in RecA1 loses contact with the phosphate from nucleotide 4. Subsequent ATP hydrolysis (NS3-Al) 
completes the ratcheting motion, where the spring helix (V232) contacts nucleotide phosphate 3 thereby shifting the RecA1 contacts with the substrate sugar-phosphate backbone one nucleotide in the $5^{\prime}$ direction (Figure $5 \mathrm{~b}$ second from bottom). While not captured as a conformational snapshot, it is reasonable to assume that following ATP hydrolysis, dissociation of the subsequent ADP and $P_{i}$ products of hydrolysis results in a restoration of the "open" conformation where RecA2 steps one nucleotide forward in the $5^{\prime}$ direction (Figure $5 \mathrm{~b}$ bottom).

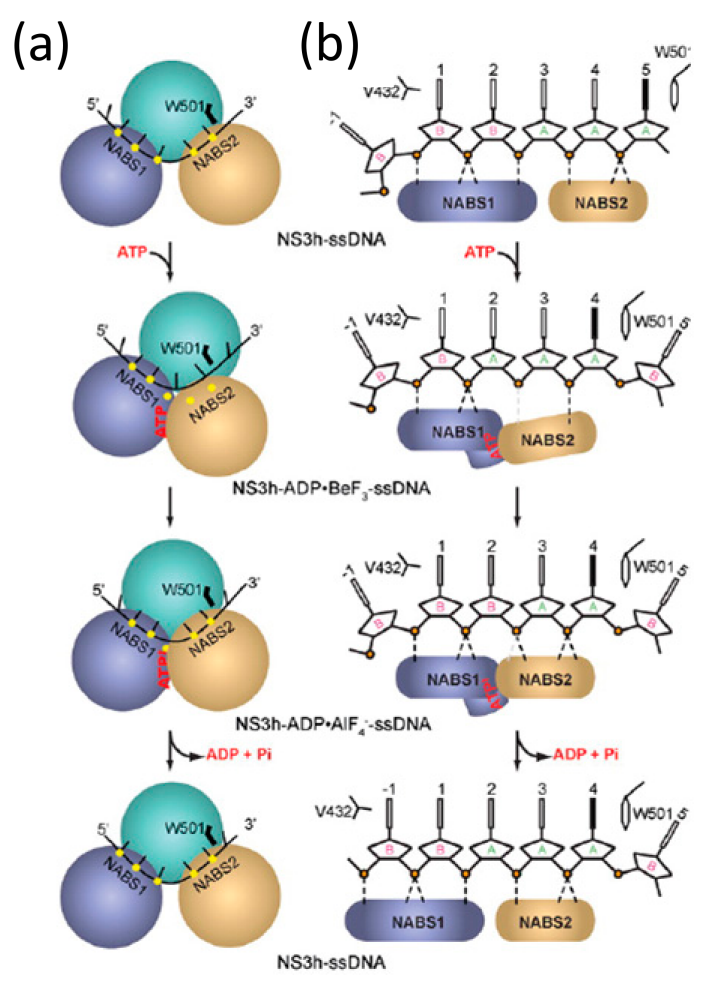

Figure 5. A schematic summarizing (a) the translocation of RecA2 (abbreviated as NABS1 in the figure) and RecA1 (abbreviated as NABS2 in the figure) $3^{\prime}$ to $5^{\prime}$ on a ssDNA substrate, which was obtained by analyzing the RecA1/RecA2 movements of NS3 in different conformational snapshots; (b) The number of RecA1/RecA2 contacts over ATP binding, hydrolysis, and release are quantified. This figure is reused with the expressed permission of Rice and colleagues [52].

\section{DEAH/RHA C-Terminal Domain Interactions}

The primary contacts between the CTD and the nucleic acid substrate occur outside the ratchet helix. In both MLE and Prp43p, minor protein RNA contacts exist in the OB and WH sub-domains. As above, OB forms a 5'-nucleic acid channel with the RecA2 domain and RL whereas WH forms a $3^{\prime}$ nucleic acid channel with the RecA1 domain (Figure 1). In MLE, RL provides several base-specific contacts towards the $5^{\prime}$-end (RecA2 portion) of the RNA substrate, whereas the Prp43p RL does not display any specific contacts with its RNA substrate.

In the Ski2-like helicases Mtr4 and Hel308, the ratchet helix provides many protein-nucleic acid contacts in the form of arginine, glutamate, and tryptophan residues [32,60,61]. Through structure-guided mutations, it was shown that the ratchet helix is important to helicase translocation and unwinding activity in Ski2-like helicases [32,60,61]. In DEAH/RHA helicases, a homologous helix-bundle domain exists, which was named after the Ski2-like ratchet sub-domain. However, the ratchet helix interacts with the RNA substrate in neither co-crystal structures of MLE-rU-TR [23] and Prp43p-rU-GR [44,45]. The RL sub-domain in DEAH/RHA helicases thus does not function in a ratchet mechanism as was proposed in Ski2-like helicases. 
Whereas HCV NS3 shares a common helicase core region with DEAH/RHA helicases (Figure 3), the CTD differ drastically both in structure and range of motion (Figure 6). Unlike the CTD of HCV NS3, the co-crystal structures of Prp43p-ADP [21,22], MLE-rU-Al [23], Prp43p-rU-GR [44,45], and Prp43p-Be [44] reveal that the most significant domain motion of DEAH/RHA helicases is an $\sim 30^{\circ}$ rotation of the CTDs (WH, RL, OB, and CTE). A counter-clockwise rotation occurs upon binding an RNA substrate in the ground and transition states as well as in the absence of an RNA substrate in the post-hydrolysis state (Figure 6). The counter-clockwise rotation results in more protein-protein contacts between the $\mathrm{OB}$ domain and the HP motif, resulting in the formation of a $5^{\prime}$ nucleic acid channel with numerous sugar-phosphate backbone interacting residues coming primarily from an OB-fold loop and RecA2 motif IV residues. Furthermore, the rotation results in the constriction of the $3^{\prime}$ nucleic acid channel, where a proline residue from $\mathrm{WH}$ and an arginine from motif $\mathrm{Ib}$ in the RecA1 domain constrict the $3^{\prime}$-end of the nucleic acid substrate $[23,44,45]$. The CTD rotation occurs in such a fashion that RL, OB, and CTE travel furthest, whereas WH is comparatively stationary. For this reason, WH appears to act as the hinge upon which the rest of the CTD rotates (Figure 6).
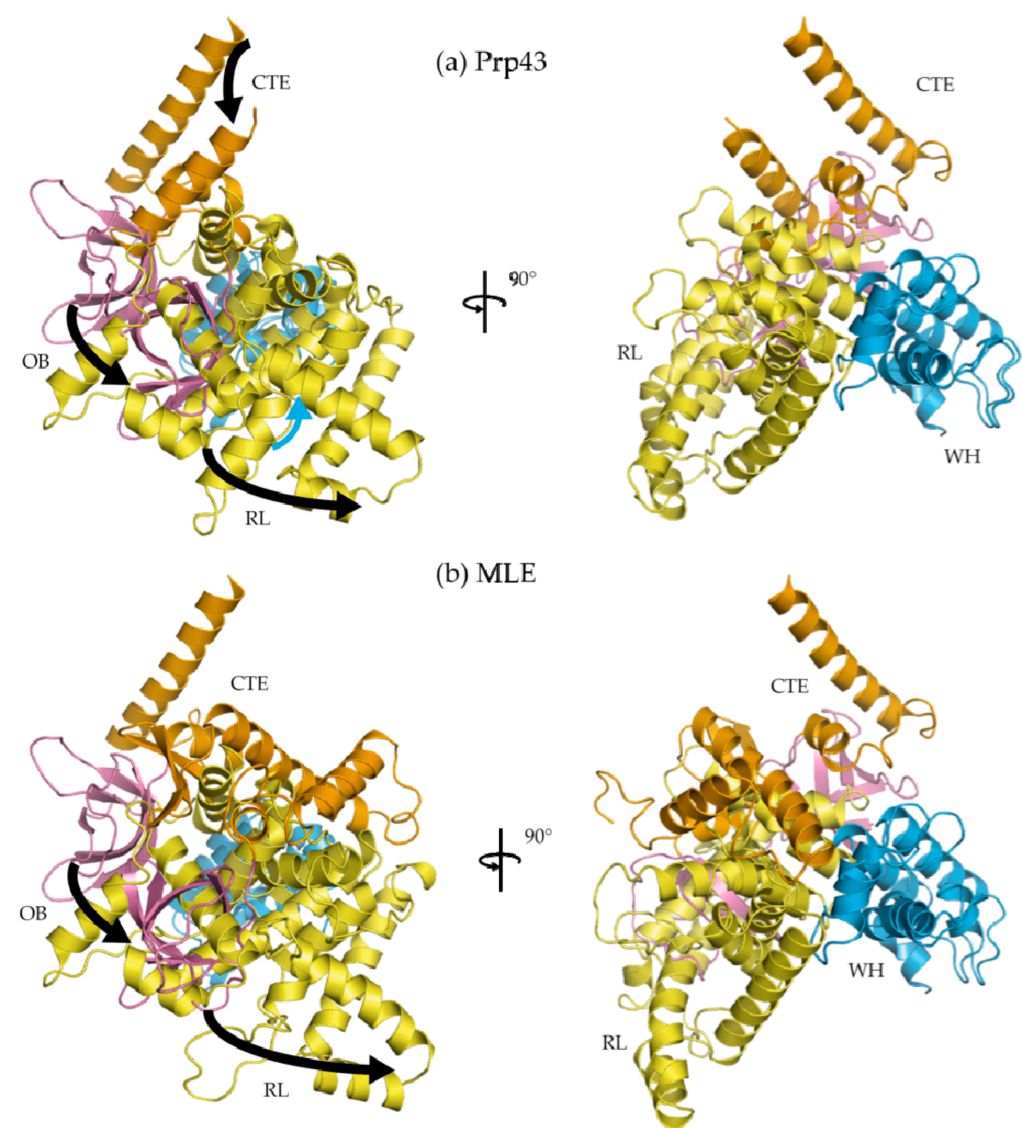

(b) MLE

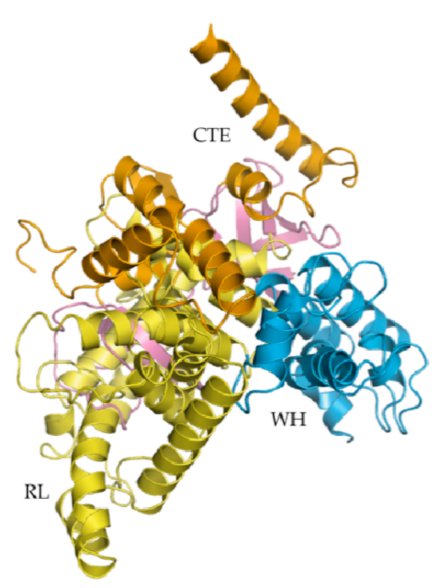

Figure 6. C-terminal domain (CTD) rotates upon binding a nucleic acid substrate. (a) Structures of Prp43p CTD bound to ADP. $\mathrm{BeF}_{3}{ }^{-}$complexed (Prp43p-rU-GR; PDB 5LTA) and not complexed with RNA (Prp43p-Be; PDB 5LTJ); (b) Structure of MLE bound to ADP. AlF ${ }_{4}^{-}$complexed with RNA (MLE-rU-TR; PDB 5AOR) was superposed with Prp43p CTD bound to ADP. $\mathrm{BeF}_{3}{ }^{-}$but not complexed with RNA (Prp43p-Be). All structures were superposed via their RecA1 domain. From both (a) and (b), rotations of $\sim 30^{\circ}$ from the $\mathrm{OB}, \mathrm{RL}$, and CTE sub-domains are observed. WH is comparatively stationary, suggesting the $\mathrm{WH}$ acts as a hinge for the rotation of the CTD.

The DEAH/RHA family appears to be unique amongst DExH proteins in the ability to rotate its accessory CTD. In the co-crystal structures of the Ski2-like helicases, Mtr4 and Hel308, no independent CTD conformational changes are observed upon binding an RNA substrate [32,60,61]. While large 
changes in helicase conformation are generally ATP-dependent, the CTD rotation appears to initially be an ATP-independent process. The binding of $\mathrm{ADP} \cdot \mathrm{BeF}_{3}{ }^{-}$is not sufficient to cause a CTD rotation; only upon binding the RNA substrate is a CTD rotation observed. However, upon ATP hydrolysis, as represented by the Prp43p-ADP co-crystal structures [21,22], CTD rotation is also observed. In an insightful experiment guided by the co-crystal structure, Prp43p-rU-GR, a disulfide bond was used to lock the CTD into a rotated state [44]. This mutation resulted in impaired unwinding capabilities, which demonstrates that the observed CTD rotation is crucial to DEAH/RHA helicase activity.

\section{Outlook}

The co-crystal structures of MLE-rU-TR and Prp43p-rU-GR have resulted in various different hypotheses regarding the manner in which DEAH/RHA helicases translocate. Prabu and colleagues propose that upon ATP hydrolysis MLE uses motif IVa (hook loop) from RecA2 to pull the $5^{\prime}$-end of the nucleic acid substrate into the helicase core [23], whereas Tauchert and colleagues propose that Prp43p translocates through a mechanism involving motif $\mathrm{Ib}$ (hook turn) that is incompatible with MLE [44]. He and colleagues further explain the dependence on motif $\mathrm{Ib}$ by proposing that the $3^{\prime}$ nucleic acid channel formed by the motif $\mathrm{Ib}$ arginine and the $\mathrm{WH}$ proline acts as a $3^{\prime}$-bookend [45]. As such, it is proposed that motif $\mathrm{Ib}$ serves a role similar to the ratchet helix in Ski2-like helicases and the CTD tryptophan gatekeeper residue in NS3/NPH-II helicases [45]. In conjunction with the HP motif (the “5'-bookend"), the motif Ib $3^{\prime}$-bookend enforces the number of nucleotides within the helicase core [45]. Similar to the translocation mechanism proposed for HCV NS3 [52,56], He and colleagues argue that Prp43p opens its helicase core after ATP hydrolysis and translocates forward in a $3^{\prime}-5^{\prime}$ direction during ATP binding [45].

In addition to more extensive biochemical studies, a co-crystal structure of an open conformation DEAH/RHA helicase bound to a nucleic acid substrate is required to shed further light on the translocation mechanism of DEAH/RHA helicases. Despite the fixation on specific motifs to effect translocation, structure guided mutations to (1) the RecA2 and OB residues on the $5^{\prime}$-end; (2) motif Ia pincer arginines; and (3) motif $\mathrm{Ib}$, Ic, and WH residues on the $3^{\prime}$-end clearly implicate (1)-(3) in DEAH/RHA helicase translocation [21-23,44,45,53]. Regardless of the translocation mechanism, the various structures of Prp43p and MLE demonstrate that CTD rotation works in conjunction with dynamic motifs from RecA2 (IVa, V, and VI) to process their substrates.

How DEAH/RHA nucleic acid substrate translocation couples with nucleic acid secondary structure unwinding is currently unknown. Due to the inherent difficulty in crystallizing highly dynamic helicases, only a handful of DEAD/DExH-box proteins bound to biological substrates exist. Many unanswered questions in relation to substrate recognition, translocation, and unwinding thus remain. How do DEAH/RHA helicase conformations change in the absence of an ATP analog? How do DEAH/RHA helicases interact with canonical and non-canonical nucleic acid structures, such as G-quadruplexes? We await further co-crystal structures of helicases bound to biological substrates to answer these questions.

Acknowledgments: Michael C. Chen was a recipient of a Cambridge Trust Studentship and a member of the NIH Oxford-Cambridge Scholars Program. Supported by the Intramural Program of the National Heart, Lung, and Blood Institute, NIH. Thanks to Meigang Gu and Charles M. Rice for agreeing to the reproduction of Figure 5 in this review. Thanks to Christopher Jones for helpful discussions.

Author Contributions: Michael C. Chen and Adrian R. Ferré-D'Amaré wrote the manuscript.

Conflicts of Interest: The authors declare no competing financial interests.

\section{References}

1. Abdelhaleem, M.; Maltais, L.; Wain, H. The human DDX and DHX gene families of putative RNA helicases. Genomics 2003, 81, 618-622. [CrossRef]

2. Jankowsky, E.; Jankowsky, A. The DExH/D protein family database. Nucleic Acids Res. 2000, 28, 333-334. [CrossRef] [PubMed] 
3. Fairman-Williams, M.E.; Guenther, U.-P.; Jankowsky, E. SF1 and SF2 helicases: Family matters. Curr. Opin. Struct. Biol. 2010, 20, 313-324. [CrossRef] [PubMed]

4. Fullam, A.; Schröder, M. DExD/H-box RNA helicases as mediators of anti-viral innate immunity and essential host factors for viral replication. Biochim. Biophys. Acta 2013, 1829, 854-865. [CrossRef] [PubMed]

5. Singleton, M.R.; Dillingham, M.S.; Wigley, D.B. Structure and mechanism of helicases and nucleic acid translocases. Annu. Rev. Biochem. 2007, 76, 23-50. [CrossRef] [PubMed]

6. Martin, R.; Straub, A.U.; Doebele, C.; Bohnsack, M.T. DExD/H-box RNA helicases in ribosome biogenesis. RNA Biol. 2013, 10, 4-18. [CrossRef] [PubMed]

7. Fuller-Pace, F.V. DExD/H box RNA helicases: Multifunctional proteins with important roles in transcriptional regulation. Nucleic Acids Res. 2006, 34, 4206-4215. [CrossRef] [PubMed]

8. Rocak, S.; Linder, P. DEAD-box proteins: The driving forces behind RNA metabolism. Nat. Rev. Mol. Cell Biol. 2004, 5, 232-241. [CrossRef] [PubMed]

9. Tanner, N.K.; Linder, P. DExD/H box RNA helicases: From generic motors to specific dissociation functions. Mol. Cell 2001, 8, 251-262. [CrossRef]

10. Silverman, E.; Edwalds-Gilbert, G.; Lin, R.-J. DExD/H-box proteins and their partners: Helping RNA helicases unwind. Gene 2003, 312, 1-16. [CrossRef]

11. Cordin, O.; Banroques, J.; Tanner, N.K.; Linder, P. The DEAD-box protein family of RNA helicases. Gene 2006, 367, 17-37. [CrossRef] [PubMed]

12. Linder, P.P. Dead-box proteins: A family affair-Active and passive players in RNP-remodeling. Nucleic Acids Res. 2006, 34, 4168-4180. [CrossRef] [PubMed]

13. Linder, P.; Jankowsky, E. From unwinding to clamping-The DEAD box RNA helicase family. Nat. Rev. Mol. Cell Biol. 2011, 12, 505-516. [CrossRef] [PubMed]

14. Jankowsky, E. RNA helicases at work: Binding and rearranging. Trends Biochem. Sci. 2011, 36, 19-29. [CrossRef] [PubMed]

15. Fuller-Pace, F.V. DEAD box RNA helicase functions in cancer. RNA Biol. 2013, 10, 121-132. [CrossRef] [PubMed]

16. Abdelhaleem, M. Do human RNA helicases have a role in cancer? Biochim. Biophys. Acta 2004, 1704, $37-46$. [CrossRef] [PubMed]

17. Abdelhaleem, M. Over-expression of RNA helicases in cancer. Anticancer Res. 2004, 24, 3951-3953. [PubMed]

18. Robert, F.; Pelletier, J. Perturbations of RNA helicases in cancer. Wiley Interdiscip. Rev. 2013, 4, 333-349. [CrossRef] [PubMed]

19. Wolfe, A.L.; Singh, K.; Zhong, Y.; Drewe, P.; Rajasekhar, V.K.; Sanghvi, V.R.; Mavrakis, K.J.; Jiang, M.; Roderick, J.E.; Van der Meulen, J.; et al. RNA G-quadruplexes cause eIF4A-dependent oncogene translation in cancer. Nature 2014, 513, 65-70. [CrossRef] [PubMed]

20. He, Y.; Andersen, G.R.; Nielsen, K.H. The function and architecture of DEAH/RHA helicases. Biomol. Concepts 2011, 2, 315-326. [CrossRef] [PubMed]

21. Walbott, H.; Mouffok, S.; Capeyrou, R.; Lebaron, S.; Humbert, O.; van Tilbeurgh, H.; Henry, Y.; Leulliot, N. Prp43p contains a processive helicase structural architecture with a specific regulatory domain. EMBO J. 2010, 29, 2194-2204. [CrossRef] [PubMed]

22. He, Y.; Andersen, G.R.; Nielsen, K.H. Structural basis for the function of DEAH helicases. EMBO Rep. 2010, 11, 180-186. [CrossRef] [PubMed]

23. Prabu, J.R.; Müller, M.; Thomae, A.W.; Schüssler, S.; Bonneau, F.; Becker, P.B.; Conti, E. Structure of the RNA Helicase MLE Reveals the Molecular Mechanisms for Uridine Specificity and RNA-ATP Coupling. Mol. Cell 2015, 60, 487-499. [CrossRef] [PubMed]

24. Lattmann, S.; Giri, B.; Vaughn, J.P.; Nagamine, Y.; Akman, S.A. Role of the amino terminal RHAU-specific motif in the recognition and resolution of guanine quadruplex-RNA by the DEAH-box RNA helicase RHAU. Nucleic Acids Res. 2010, 38, 6219-6233. [CrossRef] [PubMed]

25. Murat, P.; Balasubramanian, S. Existence and consequences of G-quadruplex structures in DNA. Curr. Opin. Genet. Dev. 2014, 25, 22-29. [CrossRef] [PubMed]

26. Heddi, B.; Cheong, V.V.; Martadinata, H.; Phan, A.T. Insights into G-quadruplex specific recognition by the DEAH-box helicase RHAU: Solution structure of a peptide-quadruplex complex. Proc. Natl. Acad. Sci. USA 2015, 112, 9608-9613. [CrossRef] [PubMed] 
27. Meier, M.; Patel, T.R.; Booy, E.P.; Marushchak, O.; Okun, N.; Deo, S.; Howard, R.; McEleney, K.; Harding, S.E.; Stetefeld, J.; et al. Binding of G-quadruplexes to the N-terminal recognition domain of the RNA helicase associated with AU-rich element (RHAU). J. Biol. Chem. 2013, 288, 35014-35027. [CrossRef] [PubMed]

28. Tanner, N.K.; Cordin, O.; Banroques, J.; Doère, M.; Linder, P. The Q motif: A newly identified motif in DEAD box helicases may regulate ATP binding and hydrolysis. Mol. Cell 2003, 11, 127-138. [CrossRef]

29. Robert-Paganin, J.; Halladjian, M.; Blaud, M.; Lebaron, S.; Delbos, L.; Chardon, F.; Capeyrou, R.; Humbert, O.; Henry, Y.; Henras, A.K.; et al. Functional link between DEAH/RHA helicase Prp43 activation and ATP base binding. Nucleic Acids Res. 2017, 45, 1539-1552. [CrossRef] [PubMed]

30. Kim, J.L.; Morgenstern, K.A.; Griffith, J.P.; Dwyer, M.D.; Thomson, J.A.; Murcko, M.A.; Lin, C.; Caron, P.R. Hepatitis C virus NS3 RNA helicase domain with a bound oligonucleotide: The crystal structure provides insights into the mode of unwinding. Structure 1998, 6, 89-100. [CrossRef]

31. Luo, D.; Xu, T.; Watson, R.P.; Becker, D.S.; Sampath, A.; Jahnke, W.; Yeong, S.S.; Wang, C.H.; Lim, S.P.; Strongin, A.; et al. Insights into RNA unwinding and ATP hydrolysis by the flavivirus NS3 protein. EMBO J. 2008, 27, 3209-3219. [CrossRef] [PubMed]

32. Büttner, K.; Nehring, S.; Hopfner, K.-P. Structural basis for DNA duplex separation by a superfamily-2 helicase. Nat. Struct. Mol. Biol. 2007, 14, 647-652. [CrossRef] [PubMed]

33. Yang, Q.; Del Campo, M.; Lambowitz, A.M.; Jankowsky, E. DEAD-Box Proteins Unwind Duplexes by Local Strand Separation. Mol. Cell 2007, 28, 253-263. [CrossRef] [PubMed]

34. Chen, M.C.; Murat, P.; Abecassis, K.; Ferré-D'Amaré, A.R.; Balasubramanian, S. Insights into the mechanism of a G-quadruplex-unwinding DEAH-box helicase. Nucleic Acids Res. 2015, 43, 2223-2231. [CrossRef] [PubMed]

35. Pyle, A.M.; Jankowsky, E.; Gross, C.H.; Shuman, S. The DExH protein NPH-II is a processive and directional motor for unwinding RNA. Nature 2000, 403, 447-451.

36. Myong, S.; Bruno, M.M.; Pyle, A.M.; Ha, T. Spring-loaded mechanism of DNA unwinding by hepatitis C virus NS3 helicase. Science 2007, 317, 513-516. [CrossRef] [PubMed]

37. Myong, S.; Ha, T. Stepwise translocation of nucleic acid motors. Curr. Opin. Struct. Biol. 2010, 20, $121-127$. [CrossRef] [PubMed]

38. Tippana, R.; Hwang, H.; Opresko, P.L.; Bohr, V.A.; Myong, S. Single-molecule imaging reveals a common mechanism shared by G-quadruplex-resolving helicases. Proc. Natl. Acad. Sci. USA 2016, 113, 8448-8453. [CrossRef] [PubMed]

39. Koh, H.R.; Xing, L.; Kleiman, L.; Myong, S. Repetitive RNA unwinding by RNA helicase A facilitates RNA annealing. Nucleic Acids Res. 2014, 42, 8556-8564. [CrossRef] [PubMed]

40. Cheng, W.; Arunajadai, S.G.; Moffitt, J.R.; Tinoco, I.; Bustamante, C. Single-base pair unwinding and asynchronous RNA release by the hepatitis C virus NS3 helicase. Science 2011, 333, 1746-1749. [CrossRef] [PubMed]

41. Pyle, A.M. Translocation and unwinding mechanisms of RNA and DNA helicases. Annu. Rev. Biophys. 2008, 37, 317-336. [CrossRef] [PubMed]

42. Dumont, S.; Cheng, W.; Serebrov, V.; Beran, R.K.; Tinoco, I.; Pyle, A.M.; Bustamante, C. RNA translocation and unwinding mechanism of HCV NS3 helicase and its coordination by ATP. Nature 2006, 439, 105-108. [CrossRef] [PubMed]

43. Lin, C.T.; Tritschler, F.; Lee, K.S.; Gu, M.; Rice, C.M.; Ha, T. Single-molecule imaging reveals the translocation and DNA looping dynamics of hepatitis C virus NS3 helicase. Protein Sci. 2017, 26, 1391-1403. [CrossRef] [PubMed]

44. Tauchert, M.J.; Fourmann, J.-B.; Lührmann, R.; Ficner, R. Structural insights into the mechanism of the DEAH-box RNA helicase Prp43. eLife 2017, 6, e21510. [CrossRef] [PubMed]

45. He, Y.; Staley, J.P.; Andersen, G.R.; Nielsen, K.H. Structure of the DEAH/RHA ATPase Prp43p bound to RNA implicates a pair of hairpins and motif Va in translocation along RNA. RNA 2017, 23, 1110-1124. [CrossRef] [PubMed]

46. Bigay, J.; Deterre, P.; Pfister, C.; Chabre, M. Fluoroaluminates activate transducin-GDP by mimicking the gamma-phosphate of GTP in its binding site. FEBS Lett. 1985, 191, 181-185. [CrossRef]

47. Chabre, M. Aluminofluoride and beryllofluoride complexes: A new phosphate analogs in enzymology. Trends Biochem. Sci. 1990, 15, 6-10. [CrossRef] 
48. Davies, D.R.; Hol, W.G.J. The power of vanadate in crystallographic investigations of phosphoryl transfer enzymes. FEBS Lett. 2004, 577, 315-321. [CrossRef] [PubMed]

49. Xu, Y.W.; Moréra, S.; Janin, J.; Cherfils, J. AlF3 mimics the transition state of protein phosphorylation in the crystal structure of nucleoside diphosphate kinase and MgADP. Proc. Natl. Acad. Sci. USA 1997, 94, 3579-3583. [CrossRef] [PubMed]

50. Liu, F.; Putnam, A.; Jankowsky, E. ATP hydrolysis is required for DEAD-box protein recycling but not for duplex unwinding. Proc. Natl. Acad. Sci. USA 2008, 105, 20209-20214. [CrossRef] [PubMed]

51. Mallam, A.L.; Sidote, D.J.; Lambowitz, A.M. Molecular insights into RNA and DNA helicase evolution from the determinants of specificity for a DEAD-box RNA helicase. eLife 2014, 3, e04630. [CrossRef] [PubMed]

52. Gu, M.; Rice, C.M. Three conformational snapshots of the hepatitis $C$ virus NS3 helicase reveal a ratchet translocation mechanism. Proc. Natl. Acad. Sci. USA 2010, 107, 521-528. [CrossRef] [PubMed]

53. Tanaka, N.; Schwer, B. Mutations in PRP43 that uncouple RNA-dependent NTPase activity and pre-mRNA splicing function. Biochemistry 2006, 45, 6510-6521. [CrossRef] [PubMed]

54. Chakraborty, P.; Grosse, F. Human DHX9 helicase preferentially unwinds RNA-containing displacement loops (R-loops) and G-quadruplexes. DNA Repair 2011, 10, 654-665. [CrossRef] [PubMed]

55. Creacy, S.D.; Routh, E.D.; Iwamoto, F.; Nagamine, Y.; Akman, S.A.; Vaughn, J.P. G4 Resolvase 1 Binds Both DNA and RNA Tetramolecular Quadruplex with High Affinity and Is the Major Source of Tetramolecular Quadruplex G4-DNA and G4-RNA Resolving Activity in HeLa Cell Lysates. J. Biol. Chem. 2008, 283, 34626-34634. [CrossRef] [PubMed]

56. Appleby, T.C.; Anderson, R.; Fedorova, O.; Pyle, A.M.; Wang, R.; Liu, X.; Brendza, K.M.; Somoza, J.R. Visualizing ATP-dependent RNA translocation by the NS3 helicase from HCV. J. Mol. Biol. 2011, 405, 1139-1153. [CrossRef] [PubMed]

57. Silverman, E.J.; Maeda, A.; Wei, J.; Smith, P.; Beggs, J.D.; Lin, R.-J. Interaction between a G-patch protein and a spliceosomal DEXD/H-box ATPase that is critical for splicing. Mol. Cell. Biol. 2004, 24, 10101-10110. [CrossRef] [PubMed]

58. Lebaron, S.; Papin, C.; Capeyrou, R.; Chen, Y.-L.; Froment, C.; Monsarrat, B.; Caizergues-Ferrer, M.; Grigoriev, M.; Henry, Y. The ATPase and helicase activities of Prp43p are stimulated by the G-patch protein Pfa1p during yeast ribosome biogenesis. EMBO J. 2009, 28, 3808-3819. [CrossRef] [PubMed]

59. Christian, H.; Hofele, R.V.; Urlaub, H.; Ficner, R. Insights into the activation of the helicase Prp43 by biochemical studies and structural mass spectrometry. Nucleic Acids Res. 2014, 42, 1162-1179. [CrossRef] [PubMed]

60. Weir, J.R.; Bonneau, F.; Hentschel, J.; Conti, E. Structural analysis reveals the characteristic features of Mtr4, a DExH helicase involved in nuclear RNA processing and surveillance. Proc. Natl. Acad. Sci. USA 2010, 107, 12139-12144. [CrossRef] [PubMed]

61. Taylor, L.L.; Jackson, R.N.; Rexhepaj, M.; King, A.K.; Lott, L.K.; van Hoof, A.; Johnson, S.J. The Mtr4 ratchet helix and arch domain both function to promote RNA unwinding. Nucleic Acids Res. 2014, 42, 13861-13872. [CrossRef] [PubMed]

62. Gu, M.; Rice, C.M. The Spring $\alpha$-Helix Coordinates Multiple Modes of HCV (Hepatitis C Virus) NS3 Helicase Action. J. Biol. Chem. 2016, 291, 14499-14509. [CrossRef] [PubMed]

(C) 2017 by the authors. Licensee MDPI, Basel, Switzerland. This article is an open access article distributed under the terms and conditions of the Creative Commons Attribution (CC BY) license (http://creativecommons.org/licenses/by/4.0/). 